elected to the chair of physics at Aberystwyth. In 1939, at the age of thirty-six, Williams was elected into the fellowship of the Royal Society.

Williams was distinguished both as an experimental and theoretical physicist. His experimental work was mainly concerned with studies of electronic and atomic collision processes, using the cloud chamber of C. T. R. Wilson. The most striking of his experimental achievements was the direct demonstration in 1940 by the cloud chamber method of the decay of a cosmic ray meson into an electron.

Skilful though he was as an experimenter, Williams' distinction lay perhaps even more in his rare gift of analysing in detail the mechanisms of complicated physical processes, using a minimum of mathematical analysis and a maximum of physical understanding. In this quality of mind he had something in common with Niels Bohr, in whose institute in Copenhagen Williams did some of his best work. In a series of papers on collision processes, chiefly in the Proceedings of the Royal Society, and particularly in a brilliant but little-known paper, "Correlation of Certain Collision Problems with Radiation Theory", published in Denmark in 1935, Williams showed these rare powers to the full. The development of what is now generally known as the Williams-Weiszäcker method of impact parameters, for the approximate treatment of atomic collision problems, has the valuable quality of revealing the underlying physical mechanisms, which are often obscured by the heavy mathematical machinery of more rigorous methods. A particularly fertile application of these ideas was made by Williams to predict the later verified logarithmic rise of ionization with the energy of a very fast particle. As applied to the simpler collision processes, the impact parameter method was at first sometimes thought of as only giving an approximate answer and a visualizable picture of what could be calculated exactly by orthodox quantum mechanical methods. However, in recent years it is coming to be more and more used in solving the very complicated problems of the collision of fast neutrons, protons and mesons; this is so just because the complexities of the problems have made solution by more rigorous methods either very difficult or nearly impossible.

During the War, Williams turned his powerful analytic mind to many of the most important prob. lems of the U-boat war, and made contributions of decisive importance to the winning of the campaign. His first work in this field, made during the summer of 1941, lay in the analysis of the process of attack on U-boats by aireraft. Simple but penetrating arguments, based on the actual observed facts of such attacks and on theoretical reasoning about these facts, showed that certain changes in the depthsetting and spacing of the depth charges should lead to a striking improvement in the number of U-boats sunk. The changes were made and the predicted results were attained, thus revolutionizing the attacking power of Coastal Command aireraft.

During 1942 Williams, who was then head of the Operational Research Section of Coastal Command, studied in great detail the tactics of harassing the U-boats by aireraft during their passage through the Bay of Biscay on their way from their bases to their hunting grounds. It was largely due to Williams' keen analysis and powerful advocacy that an augmented and improved 'Bay Offensive' was staged in early 1943. The results, in terms of U-boats sunk, were not only in startling agreement with his pre- dictions, but also were one of the important factors that led to the defeat of the U-boat campaign in the summer of 1943, and so made possible the serious planning of the invasion of Europe.

Part of the story of the technical battle of witsparticularly in the field of radar-the victory in which made this 'Bay Offensive' successful, has already been told. The tactical battle of wits, waged by Coastal Command and the Admiralty staffs against the U-boat command, were analysed with great insight by Williams, working in close collaboration with the Naval and Air Anti-U-boat Staffs. Some day, perhaps, it may be possible to tell much more of this fascinating story.

During the last months of his illness, when Williams took up again his favourite subject of the quantum theory of atomic collision processes, he confessed that he still found the subtle intricacies of the U-boat war of comparable intellectual interest.

Scientific men of all lands will mourn the loss of this brilliant young Welshman. His death, coming so soon after that of R. H. Fowler, means a sad weakening of the none too wide ranks of British theoretical physicists.

P. M. S. BLACKe'Tt.

\section{Prof. Marc Tiffeneau}

Maro Tuffeneau was born at Mouy on November 5, 1873. After leaving school he was apprenticed to a druggist in Sainte-Maxence for a year, after which he went to Paris, where he continued his training for two years longer. Then he studied at the Ecole supérieure de Pharmacie, where at the same time as his friends Valeur and Blaise he came under the influence of Béhal. After an academic career of exceptional brilliance, he acted for five years as a demonstrator in the department. By this time he had qualified as a pharmacist, and in this capacity was attached for many years first to the Hôpital Boucicaut and later to the Hôtel Dieu. In both those hospitals he had the good fortune to find ample facilities for research, of which he took full advantage, for in due course he shared his enthusiasm for chemistry with a large band of ardent workers, among whom Orékhoff and Mlle. Lévy were outstanding.

Tiffeneau was a man with wide interests, and the scientific aspect of medicine made a special appeal to him. It is characteristic of his versatility that he worked in Richet's laboratory and also at the Pasteur Institute, where it was at the suggestion of Roux that he decided to qualify in medicine. In $1907 \mathrm{he}$ obtained his doctorate in science, and in 1910 his doctorate in medicine. He was elected to a chair of chemistry at the Hôtel Dieu in 1924, and to a chair of pharmacology and materia medica at the Sorbonne in 1926; for a man to have held at the same time those two important chairs, and to have achieved distinction in each, is surely exceptional. In 1937 he was Dean of the Faculty of Medicine of the University of Paris. He was honoured by his election into the Académie de Médecine in 1927 and by his selection as member of the Institut de France in 1939 in succession to Urbain. He was also an Officier de la Légion d'honneur. At the time of his death on May 20, 1945, he was president of the French Chemical Society. His wife, a sister of Prof. Fourneau, survives him with two sons.

After Fittig discovered the pinacol transformation in 1859 , the mechanism of this action as well as that of the dehydration of glycols of various types 


\section{No. 3970 December I, $1945 \quad$ N A T U R E}

attracted the attention of many chemists the world over, and among those chemists Tiffeneau takes a leading place. Indeed, no one more than he had exploited this important aspect of molecular rearrangement so exhaustively and with greater experimental skill and ingenuity. Some conception of his comprehensive outlook may be gathered from a perusal of the elaborate résumé on glycols which he wrote for the "Traité de Chimie" edited by Grignard, Dupont and Locquin. By his studies on the semihydrobenzoin and semipinacolinic transpositions as well as on the vinyl dehydration of glycols, he threw much light on the question of distribution of affinity in molecules. Further, the reaction of semipinacolinic deamination furnished him with an excellent means of contrasting the migrational aptitude of hydrocarbon radicals. Among the numerous topies which he investigated may be mentioned the isomerization of epoxides, the elimination of halogen from iodohydrins, and the stereochemistry of compounds of the type of ethylhydrobenzoin. Dealing more particularly with hypnotics and anæsthetics, he advanced pharmacology by his work on the relationship between chemical constitution and physiological action, and he also experimented with the effects of adrenaline, ephedrine, hordenine, organic compounds of mercury, and many other substances.

Like Pasteur, Tiffeneau was a keen French patriot, and during the occupation of Paris by the Germans he did much to keep the spirit of research alive in the University. The news of his sudden death came as a blow to his many friends, who are not unmindful of what they owe to his inspiration.

Arex. MoKenzre.

WE regret to announce the following deaths :

Dr. F. W. Aston, F.R.S., fellow of Trinity College, Cambridge, on November 20, aged sixty-eight.

Dr. H. E. Durham, who took part in various expeditions to study tropical diseases, and in recent years was supervisor of the laboratories of $H$. P. Bulmer and Co., Ltd., on October 5, aged seventynine.

\section{NEWS and VIEWS}

\section{Nobel Prize for Chemistry for 1944 : Prof. Otto Hahn}

Prof. Otтo Hahn, to whom the Nobel Prize for Chemistry for 1944 has been awarded, in recognition of his discovery (with F. Strassmann) of the neutroninduced fission of uranium and thorium (in its chemical aspects), has for long been universally recognized as the outstanding 'radioactive' chemist of his generation. Born sixty-six years ago, he began his studies in radioactivity in his early twenties under Sir William Ramsay at University College, London, proceeding from there, as Soddy had done previously, to work for a time with Rutherford in Montreal. In London he discovered radiothorium, an intermediate product between thorium and thorium $X$, and in Montreal radioactinium - and also carried out purely physical experiments on the magnetic and electric deflexions, and on the ranges, of the $\alpha$-particles from thorium $C$. Having returned to Berlin (1906), he isolated mesothorium 1 (1907) and mesothorium 2 (1908), and from that date he continued to contribute regularly to-and in general to lead-the great advances in specialized chemical technique required for pioneering work with the heavy radioactive elements. His thirty years association with Lise Meitner (1908-38) provides a classical example of the happy collaboration of chemist and physicist to the mutual advantage of both sciences. It was terminated only by the rigour of the laws of racial discrimination which were enforced in Hitler's Germany. No doubt it is more than a slight consolation in the face of imposed separation that Meitner and Hahn should each have been able to contribute, one on the physical, the other on the chemical side, to the original elucidation of the problem of uranium fission. During the War, Hahn continued to work on the chemical side of this problem and many of the results which he and his colleagues obtained were permitted full publication by the German censor.

The award of the Nobel Prize is a fitting tribute to a scientific achievement of immense range and single- ness of purpose : Hahn may have missed the broader generalizations, the displacement law, the significance of nuclear isomerism-although he discovered the first recorded instance of this phenomenon (1921) and established its essential features as the result of masterly experimentation, he may, in later years, have been in possession of the clue to fission before he would admit it even to himself, but no single man has done more for his subject. In 1906, Rutherford wrote ("Radioactive Transformations", p. 69) "the results so far obtained by Hahn are of the greatest interest and importance"; his subsequent discoveries, over a period of forty years, have maintained that high standard throughout.

\section{Nobel Prize for Physics for 1945 : Prof. Wolfgang Pauli}

The Nobel Prize for Physics for 1945 has been awarded to Prof. Wolfgang Pauli, of the Federal Technical Highschool at Zurich, which before the War became through him a centre of theoretical physies. When the danger of a German invasion seemed imminent, he went to the Institute for Advanced Study, Princeton. Among the many brilliant disciples of Sommerfeld, Pauli and Heisenberg are the most outstanding. While he was a student, Pauli wrote the article on the "Theory of Relativity" for the "Mathematical Encyclopedia" which, to this day, is one of the best presentations of this subject. He took an active part in Bohr's interpretation of atomic spectra in terms of quantum theory, and he was the first to attribute to the electron, apart from its three ordinary quantum numbers, a fourth one, $s= \pm \frac{1}{2}$, which was, soon afterwards, recognized by Goudsmit and Uhlenbeck to be the angular momentum (spin). This led Pauli to his main discovery, the exclusion principle; originally derived from experimental facts about spectra (of helium and other atoms) it turned out to be one of the most general rules of quantum theory. It served Bohr as the main tool in his explanation of the periodic system of the elements. After Bohr's theory 